\title{
Phrasal Verbs: Usage and Acquisition
}

\author{
By Emilie Riguel
}

Phrasal verbs represent a typical feature of English. Multiword expressions, and especially phrasal verbs, can assess the level of English language proficiency. However, learners of English tend to adopt a strategy of avoidance. Unpredictable, phrasal verbs can be difficult to both understand and remember for non-English speakers, which prompted Sinclair (1996) to call them 'the scourge of the learner'. The role of multiword constructions has also been emphasized in theories of first language acquisition (Goldberg, 1995; Tomasello, 2003). They are indeed a rich and productive source of predication that children must master, doing so at very young ages. There is, nevertheless, a huge gap in the study of child language acquisition that has largely left unaddressed questions about how the child learns and acquires verb-particle constructions. The purpose of this paper is to explore the gradual development of verb-particle constructions in child language by examining longitudinal data from the spontaneous oral speech of Naima, an English-speaking girl from the Providence Corpus of the CHILDES database (MacWhinney, 2000; Demuth, Culbertson \& Alter, 2006), between ages 0;11 and 3;10. My findings also support the claim that input and interaction play a major role in the language acquisition process. Indeed, by analyzing the emergence and usage of phrasal verbs by Naima, I will thus compare the top ten verb-particle construction types used by the child and the adult. Ultimately, I will show the correlation between the most frequently used phrasal verbs in adult speech and the earliest constructions acquired by Naima.

\section{Introduction}

Definition and Background Information

Phrasal verbs are typical of the English language (Fraser, 1976; Moon, 2005, as quoted in Macmillan, 2005). As stated by McArthur (1989), they have always represented 'a vigorous part of English'. Phrasal verbs indeed make up one-third of the English verb vocabulary (Li, Zhang, Niu, Jiang, \& Srihari, 2003). Besides, there are about 3,000 established phrasal verbs in English, including 700 in everyday use (Bywater, 1969; McArthur \& Atkins, 1974; Cornell, 1985). In addition to the great number of existing phrasal verbs, new

${ }^{*} \mathrm{PhD}$ Student, University of Sorbonne Nouvelle - Paris 3, France.

https://doi.org/10.30958/ajp.1-2-3

doi=10.30958/ajp.1-2-3 
ones are constantly being coined. As noted by Bolinger (1971), they thus constitute a highly productive category: 'an explosion of lexical creativeness that surpasses anything else in our language'.

There is no universal definition of phrasal verb. Indeed, as underlined by Gardner and Davies (2007), 'linguists and grammarians struggle with nuances of phrasal verb definitions'. One of the reasons for this lack of consensus (Darwin \& Gray, 1999; Sawyer, 2000) is that some linguists qualify phrasal verb as the combination of a verb and a preposition or an adverbial particle whereas others only consider a phrasal verbs as a verb followed by an adverbial particle. Phrasal verbs have, however, traditionally been understood as consisting of a verb and an adverbial particle.

As regards to the meanings of phrasal verbs, they may range from directional, or literal, or transparent, (e.g., stand up, take away) to aspectual, or completive, (e.g., burn down, eat up) to non-compositional, or idiomatic, or opaque, (e.g., face off, figure out) (Live, 1965; Fraser, 1965, 1966; Bolinger, 1971; Makkai, 1972; König, 1973; Moon, 1997; Celce-Murcia \& LarsenFreeman, 1999). The semantic classes of phrasal verbs can thus be represented on a broad continuum between compositional (directional and aspectual) meanings and non-compositional (idiomatic) ones (Bolinger, 1971; Moon, 1998) (see Figure 1).

Figure 1. Semantic Continuum of Phrasal Verbs

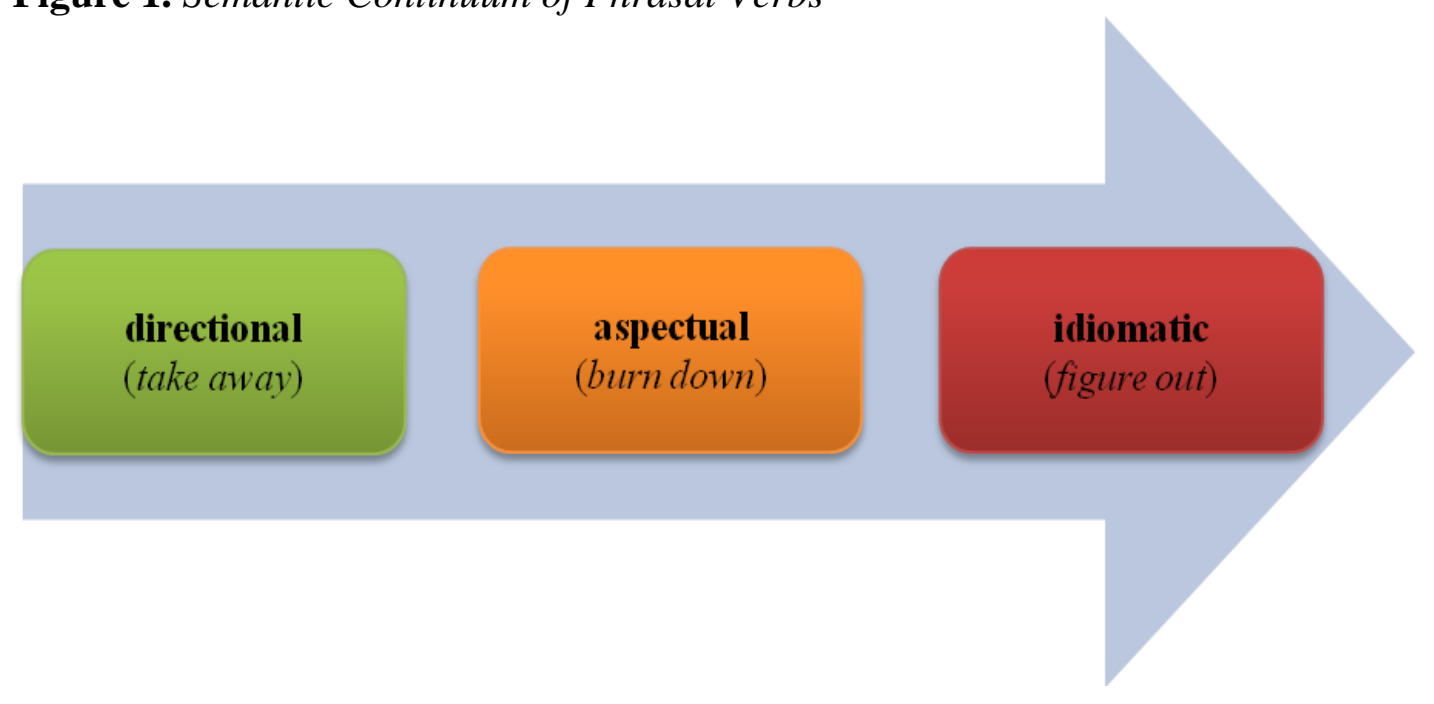

Phrasal Verbs, 'The Scourge of the Learner'

Many linguists and researchers have recognized the importance of multiword expressions as they attest to mastery of English (Klein, 1989; Folse, 2004; Wood, 2004). Phrasal verbs can thus assess the level of English language proficiency. Cowie (1993) views them as 'a nettle that has to be grasped if students are to achieve native-like proficiency in speech and writing'. As for Cullen and Sargeant (1996), they explain that 'understanding and being able to use these constructions correctly in spoken and written English is essential if the learner is to develop a complete command of the language'. 
Nonetheless, only a limited number of languages possess phrasal verbs (Celce-Murcia \& Larsen-Freeman, 1999), which necessarily limits the possibility of successful transfer (Kellerman, 1983) for those learners whose mother tongues lack verb-particle constructions.

There has been considerable discussion about the challenges imposed by phrasal verbs to foreign learners of English. Indeed, not only may verb-particle constructions have reduced syntactic flexibility, but they may also be semantically more figurative. Accordingly, for some cases, the meaning of a phrasal verb turns out to be difficult to infer from its component words. For instance, the phrasal verb 'to play something down' does not have to do with a playing event and it rather means 'to minimize the importance of something', as the following example from the British National Corpus (BNC) (Davies, 2004-) illustrates:

(1)The European Commission sought to play down fears yesterday that new European Community rules limiting imports of cheaper bananas from Latin America would force up prices for consumers.K59_1005 (BNC)

Given their complexity and their unpredictable nature, multiword expressions, and especially phrasal verbs, can be difficult to both understand and memorize for non-English speakers in the current language experience (Coady, 1997). They are a source of confusion and ambiguity - in terms of idiomaticity and polysemy, in particular (Cornell, 1985; Side, 1990; Moon, 1997; Celce-Murcia \& Larsen-Freeman, 1999; Rudzka-Ostyn, 2003) - in such a way that Sinclair (1996) called them 'the scourge of the learner'. Accordingly, second language learners of English tend to adopt an avoidance strategy with respect to phrasal verbs, preferring most of the time using single-word verbs of Latin origin. This idea of avoidance has been clearly emphasized by Bywater (1969):

'The plain fact is that what distinguishes the writing and, above all, the speech of a good foreign student from those of an Englishman is that what an Englishman writes or says is full of these expressions, whereas most foreigners are frightened of them, carefully avoid them, and sound stilted in consequence. Foreign students who enjoy being flattered on their English can best achieve this by correctly using masses of these compound verbs.'

To highlight the 'under-representation' (Levenston, 1971) of this particular category of verbs that phrasal verbs constitute, greatly puzzling to non-native speakers, a quantitative corpus study of the use of phrasal verbs has been conducted to compare learners' productions with native students' writings. All phrasal verbs have thus been extracted from the International Corpus of Learner English (ICLE) (Granger et al., 2002), the largest essay collection of advanced learners from different mother tongue backgrounds (Bulgarian, Czech, Dutch, Finnish, French, German, Italian, Polish, Russian, 
Spanish and Swedish), and from the Louvain Corpus of Native English Essays (LOCNESS) (Granger et al., 1995), the control corpus complementing ICLE.

Figure 2 shows the extent of over- and underuse of phrasal verbs by foreign learners with respect to native speakers. The results have been summarized in Table 1.

Figure 2. Extent of Over-And Underuse of Phrasal Verbs by Foreign Learners in Comparison to Native Speakers

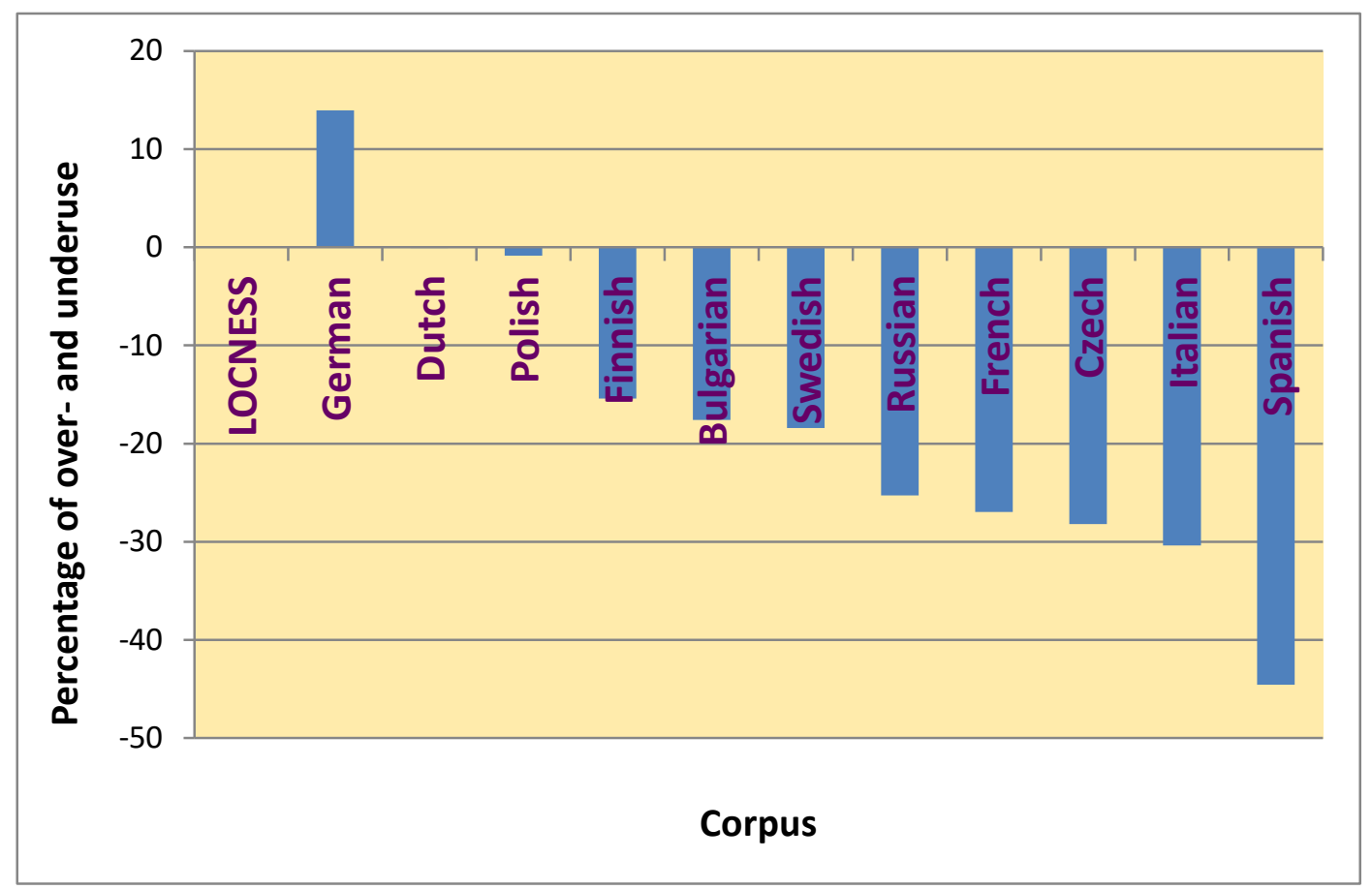

Table 1. Extent of Over-And Underuse of Phrasal Verbs by Foreign Learners in Comparison to Native Speakers

\begin{tabular}{|c|c|}
\hline Corpus & Percentage of use \\
\hline LOCNESS (control corpus) & $0 \%$ \\
\hline ICLE_German & $+13.92 \%$ \\
\hline ICLE_Dutch & $-0.1 \%$ \\
\hline ICLE_Polish & $-0.87 \%$ \\
\hline ICLE_Finnish & $-15.4 \%$ \\
\hline ICLE_Bulgarian & $-17.59 \%$ \\
\hline ICLE_Swedish & $-18.41 \%$ \\
\hline ICLE_Russian & $-25.29 \%$ \\
\hline ICLE_French & $-26.98 \%$ \\
\hline ICLE_Czech & $-28.2 \%$ \\
\hline ICLE_Italian & $-30.39 \%$ \\
\hline ICLE_Spanish & $-44.57 \%$ \\
\hline
\end{tabular}

Phrasal verbs are not universally underused by advanced foreign learners of English. Indeed, German learners stand out from all the other learner groups and they even use more phrasal verbs than native students. This much has to do 
with the fact that speakers of German have phrasal verbs in their mother tongue. As for Dutch and Polish learners, they perform in the same quantitative range as native speakers, whereas all the other learner groups use fewer phrasal verbs than native students. Finally, avoidance has above all been identified in the English of learners with a Romance native language background (e.g., Spanish, Italian, French) - languages which lack phrasal verbs.

\section{Purpose}

Much has been discussed about the numerous challenges posed by multiword expressions, and especially phrasal verbs, to foreign learners of English, given their unpredictable nature and their complexity. Nonetheless, little or no study has been done on the acquisition of verb-particle constructions by young English-speaking children. Yet, phrasal verbs represent as well one of the most challenging areas for children acquiring English as their native language.

This study explores whether children shy away from using them when they communicate. In this paper, I will then report a wide-coverage investigation of the acquisition of phrasal verbs and their usage in child speech. Studies like these can inform the development of new areas of work for language acquisition.

This paper is structured as follows: section 2 describes verb-particle constructions and related works; section 3 presents the resources and methods used in this paper. The analyses of verb-particle constructions in child speech and in adult discourse are in section 4. I finish with conclusions and possibilities of further studies.

\section{Related Work}

Multiword verbs such as phrasal verbs function as whole units. They are considered as a separate lexical unit, reflecting the semantic unit of the construction. This is indeed consistent with construction grammars, where content and form are paired to form a construction whose meaning is generally unpredictable (Fillmore, 1985, 1988; Lakoff, 1987; Langacker, 1987; Goldberg, 1995, 2003; Stefanowitsch \& Gries, 2003).

The impact of such theories on our understanding of child language acquisition has consisted in emphasizing the importance of a construction built piece by piece, 'mosaic-like' (Robert \& Chapouthier, 2006; Schmidtke-Bode, 2009), and based on lexical items rather than rules until very late. Tomasello's verb-island hypothesis (1992) thus states that the child first learns words in chunks in specific constructions. This assumption is in line with the Gestalt theory, which asserts that a perceived global form does not match the sum of stimuli that constitute it, and the perception of a part fits with our understanding of the whole. Constructions are actually first understood as a 
whole; the analysis of a verb-island construction being primarily inseparable from the individual verbs previously learned by the child. Thus, children's early grammatical knowledge consists 'not of an abstract and coherent formal grammar but rather of a loosely organized inventory of item-based construction islands' (Cameron-Faulkner, Lieven, \& Tomasello, 2003; see also Rowland, 2007). Equally supported by MacWhinney (1975, 1982, 1988), the theory of item-based learning has been identified as one of the central processes for a correct language production. Ultimately, language acquisition is a gradual process: linguistic categories are not innately given to the child, but gradually built by him from his language experiences.

In this paper, I present a wide-coverage investigation of the acquisition of phrasal verbs and their usage in child speech. More specifically, this work aims to examine the gradual development of verb-particle constructions in child language.

\section{Materials and Methods}

The analysis was carried out on the longitudinal spontaneous speech data of Naima, a monolingual English-speaking girl from the Providence Corpus of the CHILDES database (MacWhinney, 2000; Demuth, Culbertson \& Alter, 2006), between ages $0 ; 11$ and 3;10. Audio and video recordings, which began at the onset of first-word production and took place for approximately one hour every two weeks, were collected during spontaneous interactions between Naima and her mother (sometimes her father) at home. The utterances were transcribed using CHAT conventions.

For the current study, I used CLAN programs to extract all child utterances containing verb-particle constructions. Since the adult corpus was not coded, I collected the data manually.

\section{Verb-particle Constructions in Early Child Language}

\section{The Development of Verb-Particle Constructions in Early Child Language}

Movement and space are two inseparable entities; our conceptualization of the movement being indeed part of the concept of space. As stated by Vandeloise (1987), 'the movement is an aspect of the outside world and it is often inscribed in the linguistic structures'.

The child lives in a world in motion. The first child language constructions obviously arise from both the movement and space, which are especially salient for the child.

Child's early single-word utterances are called holophrases (De Laguna, 1927). They are attempts at a sentence and convey a holistic communicative intention which mainly corresponds to that of the adult language from which it

\footnotetext{
${ }^{1}$ Quotation translated by my care. Original text: 'Le mouvement est un aspect du monde extérieur souvent inscrit dans les structures linguistiques'.
} 
was acquired (Barrett, 1982; Ninio, 1992). Generally, child's first productive holophrastic utterances consist in making requests or describing dynamic events involving objects.

What are the parts of adult language utterances that young children select when they produce their first holophrases?

As Slobin (1985) explained, the answer lies in the kinds of discourse children participate with adults. This has to do mainly with the fact that certain words and phrases in adult speech are more perceptually salient than others (Slobin, 1973; Shady \& Gerken, 1999). Thus, child's initial holophrases consist of 'dynamic event words' such as up, down, on, off, etc., since adults use these words when referring to particular events (McCune, 1992, 2006; Bloom, Tinker \& Margolis, 1993). They appear quite early in child language: they are part of the first twenty lexical items learnt by English-speaking children according to Brown (1973), and are primarily spatial localizers. ${ }^{1}$ Many of these words will actually correspond to phrasal verbs in adult language (Leopold, 1939). Thus, the first stage of the development of verb-particle constructions in child language corresponds to the holophrastic use of adverbial particles, also called 'satellites '2 (Brown, 1973; Slobin, 1973; Tomasello, 1987). Their frequency in final position in the input speech accounts for their use instead of verbs (Slobin, 1973; Smiley \& Huttenlocher, 1995).

Consider the following utterances, extracted from the Providence Corpus (Demuth, Culbertson \& Alter, 2006):

(2) NAIMA: up Daddy. $(1 ; 4,03)$

FATHER: oh you wanna get picked up oh that was in the way.

FATHER: that was in the way you wanted to get picked up and that was in the way?

(3) MOTHER: oh oh oh not in the mouth please.

MOTHER: we don't eat our trains in this house.

MOTHER: yucky.

MOTHER: are you a dog?

MOTHER: are you pretending to be a dog?

MOTHER: yeah you can take it out of your mouth yourself I think.

NAIMA: down. $(1 ; 3,26)$

MOTHER: it did fall down didn't it?

NAIMA: train down.

NAIMA: train down.

MOTHER: the train fell down.

MOTHER: did it fall down?

NAIMA: yy yy yy yy yy.

MOTHER: think it did.

MOTHER: train fell down.

\footnotetext{
${ }^{1}$ The spatial location is indeed cognitively simpler.

${ }^{2}$ Note that English is a satellite-framed language; the trajectory of the event being expressed in an element of the verbal periphery, or 'satellite'. By contrast, languages that express the path in the verb are called verb-framed languages (French, for instance).
} 
Clearly, Naima's holophrastic use of up in (2) and down in (3) conveys a spatial meaning corresponding precisely to a vertical path, which is characteristic of the first uses of particles. Moreover, here, up and down are said to be 'coloured' particles because they are highly charged semantically, so that Tomasello (1987) considers them as 'verb-like'. Thus, the particle up used by Naima in (2) might actually be, in a way, the equivalent of a truncated phrasal verb and be glossed in 'pick me up'. There would then be an implicit predicative relation in holophrases. Accordingly, in the acquisition of verbparticle constructions, the child's holophrastic stage, beginning at $0 ; 11,28$ and being predominant up to $1 ; 4,03$ in Naima's data (see Figure 3), does not so much mark a spatial relationship between objects and people but rather a child's query about an action to be performed. This is indeed particularly emphasized in (2) with the adding of 'Daddy', which functions as an addition to Naima's holophrastic statement, thus clarifying her adult interlocutor. Besides, the video clearly shows Naima grabbing her father's T-shirt and straightening her arms up; thus confirming an orientation towards the purpose of the action.

Figure 3. Gradual Acquisition of Verb-Particle Constructions by Naima (Providence Corpus)

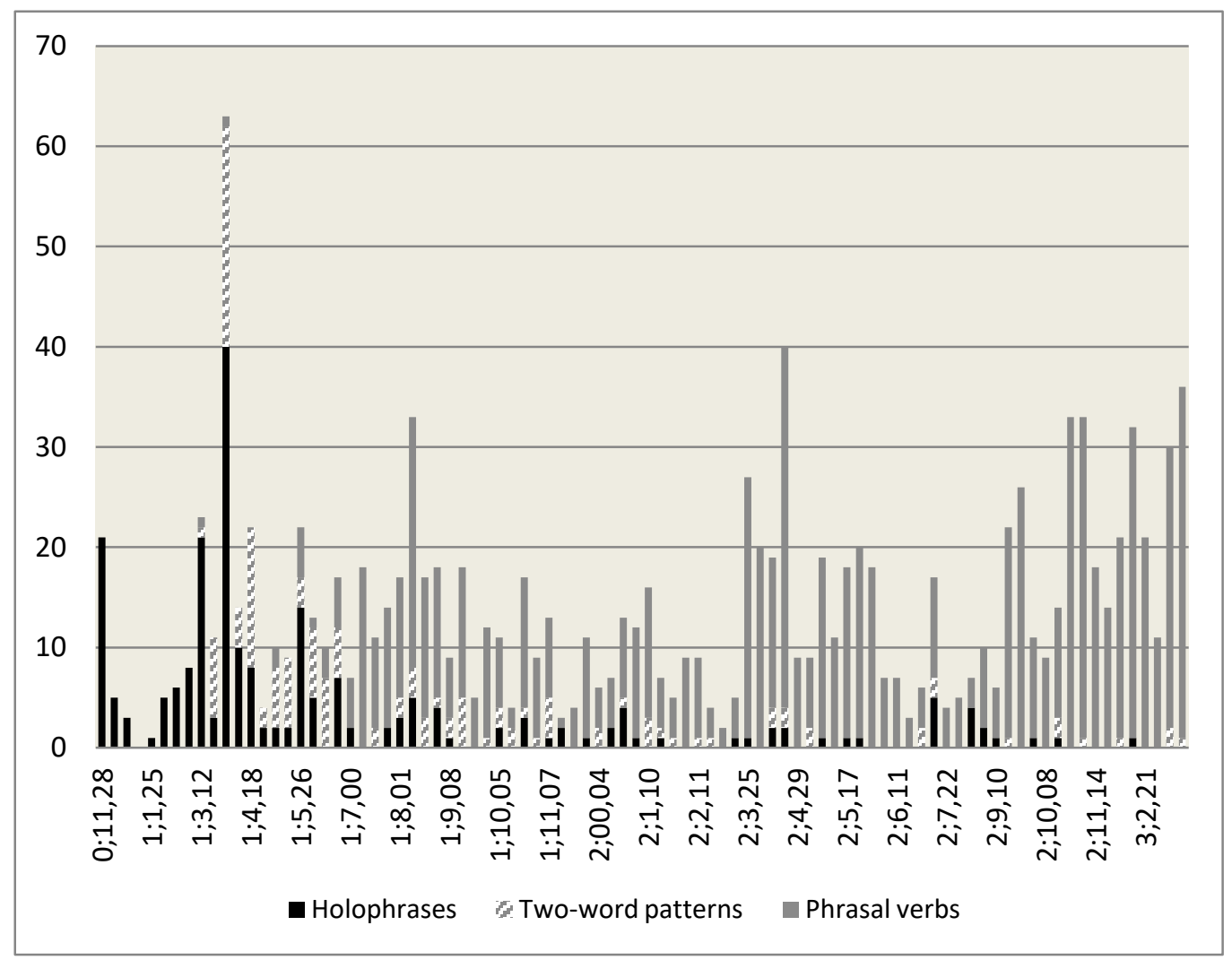

As soon as the child is able to produce more than one word, his earliest multiword utterances refer to many of the same kinds of things he talked about previously with his holophrases (Damon \& Lerner, 2006). Child's initial 
multiword constructions would thus ensue from his earlier holophrases. Indeed, this is especially the case in example (3) with Naima's holophrastic use of down and her initial two-word utterance 'train down'; Naima commenting on a toy that has fallen down and that is now on the floor. The second stage of the development of phrasal verb constructions in child language usually follows the pattern $X$ up, $X$ down, $X$ in, $X$ out, $X$ on, $X$ off, etc., $X$ being a noun phrase (Tomasello, 2003). This second period, starting at 1;3,26 in Naima's data and being predominant up to $1 ; 6,21$ (see Figure 3), reflects, in a way, the beginnings of predication since down is predicated of 'train'. Again, like in (2), we have here, with 'train down', the vertical trajectory prototypically expressed by down giving way to an orientation toward both the location at the endpoint and the result of the action. Similar examples can be found in the corpus:

(4) NAIMA: shoes on.

(5) NAIMA: microphone off.

Examples (4) and (5) can thus be respectively glossed in 'put my shoes on' and 'turn the microphone off'.

Finally, the last stage of the acquisition of phrasal verb constructions corresponds to the period when children are able to produce complete constructions combining a verb and a particle (with an object, if the verb is a transitive one). In the corpus, Naima produces her first phrasal verb at $1 ; 3,12$ ('fall down'). Her verb-particle constructions seem to become predominant over the two previous stages by 1;6,21 (see Figure 3), and they are getting more complex as Naima is growing older:

(6) NAIMA: Mommy clean up yy $(1 ; 8)$

(7) NAIMA: I took it off because I don't wanna have this on me $(2 ; 10)$

(8) NAIMA: I have to watch out for it so it yy doesn't go in the food $(3 ; 1)$

The three stages of the development of verb-particle constructions are presented in Figure 3.

\section{The Influence of the Input on the Acquisition of Phrasal Verbs}

Whether it be the language addressed directly to the child, or the language spoken around him, the input does not only have a triggering role, but it also plays a crucial role in the acquisition process.

The factors determining the acquisition of verb-particle constructions are related to language use and frequency of input (Rice, 1999). Naima's and her mother's data are summarized in Table 2.

Table 2. Verb-Particle Construction Usage in the Child's and Adult's Data

\begin{tabular}{|c|c|c|}
\hline Verb-particle constructions & Child & Adult \\
\hline Number of phrasal verb tokens & 862 & 4019 \\
\hline Number of phrasal verb types & 185 & 472 \\
\hline Number of support verb types & 109 & 246 \\
\hline
\end{tabular}


This section examines and compares the top ten verb-particle construction types produced by Naima and her mother. The results are listed in Table 3. From these, 8 out of the 12 are exactly the same, differing only in the order in which they appear. The results obtained clearly indicate that the most frequently used verb-particle constructions in child data follow very closely adult usage. Besides, it is interesting to notice that the verbs used in the most frequent phrasal verbs in Naima's and her mother's data belong to the class of 'light verbs'. And, indeed, it is not surprising since, given their frequency of use, they are acquired at a very early age by children and they act as centers of gravity from which more specific instances can be learnt (Goldberg, 1995, 1998, 1999).

Table 3. Top Verb-particle Constructions for the Child and the Adult

\begin{tabular}{|c|c|c|c|c|c|}
\hline Rank & Child VPC & Child Freq & Adult VPC & Adult Freq & Child Rank \\
\hline $\mathbf{1}$ & take off & $\mathbf{5 0}$ & put on & 219 & 2 \\
\hline $\mathbf{2}$ & put on & $\mathbf{4 2}$ & take off & 199 & 1 \\
\hline $\mathbf{3}$ & fall down & $\mathbf{3 0}$ & clean up & 125 & 7 \\
\hline $\mathbf{4}$ & put back & $\mathbf{2 8}$ & get out & 114 & 8 \\
\hline $\mathbf{5}$ & come back & $\mathbf{2 7}$ & fall down & 101 & 3 \\
\hline $\mathbf{6}$ & take out & $\mathbf{2 6}$ & take out & 96 & 6 \\
\hline $\mathbf{7}$ & clean up & $\mathbf{2 3}$ & put back & 93 & 4 \\
\hline $\mathbf{8}$ & get out & $\mathbf{2 2}$ & put in & 89 & 9 \\
\hline $\mathbf{9}$ & come out & $\mathbf{2 1}$ & put away & 80 & 23 \\
\hline $\mathbf{9}$ & put in & $\mathbf{2 1}$ & pick up & 65 & 11 \\
\hline $\mathbf{1 0}$ & go away & $\mathbf{2 0}$ & wake up & 64 & 10 \\
\hline $\mathbf{1 0}$ & wake up & $\mathbf{2 0}$ & come out & 61 & 9 \\
\hline
\end{tabular}

Furthermore, the hypothesis that there would be a correlation between the most frequently used phrasal verbs in adult speech and the earliest constructions acquired by Naima is confirmed by the data, as shown in Table 4 . Indeed, 19 out of 33 of the most frequent verb-particle constructions in the mother's data are acquired by Naima between $1 ; 3,12$ and $1 ; 8,08$, and it is greatly significant given that Naima was followed from age $0 ; 11$ to $3 ; 10$.

\section{Conclusions}

This paper explored the emergence and gradual development of verbparticle constructions in child language. The child's data show that the acquisition of phrasal verbs by young English-speaking children generally follows three stages, from incomplete forms to complete constructions. First, child's initial utterances consist of holophrastic uses of adverbial particles, which seem to behave in a 'verb-like' manner and convey the meaning of an entire sentence. Secondly, the two-word utterance stage, combining a noun phrase and a particle, emerges as the beginnings of predication. Thirdly, the child is able to successfully produce complete verb-particle constructions. 
This work also examined and compared the top ten verb-particle construction types in Naima's data and her mother's. The results show that the child follows very closely adult usage in terms of the phrasal verb types and is sensitive to their frequencies, thus displaying similar distributions to the adult.

Finally, the hypothesis tested confirms the correlation between the earliest verb-particle constructions acquired by Naima and the most frequent phrasal verbs used by her mother.

The data from spontaneous dialogical contexts may thus give a new insight on how phrasal verbs develop in child language.

Table 4. Results of the Hypothesis Test

\begin{tabular}{|c|c|c|}
\hline $\begin{array}{c}\text { Most frequent PVs } \\
\text { (Mother) }\end{array}$ & $\begin{array}{c}\text { Number of tokens } \\
\text { (Mother) }\end{array}$ & Age of emergence (Child) \\
\hline put on & 219 & $1 ; 6,21$ \\
\hline take off & 199 & $1 ; 6,21$ \\
\hline clean up & 125 & $1 ; 6,09$ \\
\hline get out & 114 & $1 ; 7,00$ \\
\hline fall down & 101 & $1 ; 3,12$ \\
\hline take out & 96 & $1 ; 8,08$ \\
\hline put back & 93 & $1 ; 7,10$ \\
\hline put in & 89 & $1 ; 8,19$ \\
\hline put away & 80 & $1 ; 7,17$ \\
\hline pick up & 65 & $1 ; 6,09$ \\
\hline wake up & 64 & $1 ; 8,08$ \\
\hline come out & 61 & $2 ; 4,11$ \\
\hline pick out & 61 & $2 ; 3,25$ \\
\hline turn off & 50 & $1 ; 9,23$ \\
\hline come back & 49 & $1 ; 6,09$ \\
\hline sit down & 48 & $1 ; 7,10$ \\
\hline take away & 44 & $1 ; 7,25$ \\
\hline go down & 43 & $2 ; 6,11$ \\
\hline come on & 42 & $3 ; 3,26$ \\
\hline hold on & 42 & $2 ; 10,08$ \\
\hline put down & 42 & $2 ; 4,26$ \\
\hline hang up & 40 & $2 ; 1,10$ \\
\hline get off & 39 & $1 ; 5,26$ \\
\hline go back & 39 & $2 ; 5,17$ \\
\hline go out & 35 & $2 ; 00,04$ \\
\hline dress up & 34 & $1 ; 7,10$ \\
\hline turn on & 34 & $1 ; 7,10$ \\
\hline come off & 33 & $2 ; 5,20$ \\
\hline find out & 33 & $1 ; 7,25$ \\
\hline get down & 33 & $1 ; 8,01$ \\
\hline fit in & 32 & 1 \\
\hline figure out & 31 & $2 ; 11,14$ \\
\hline go in & 30 & $1 ; 8,01$ \\
\hline
\end{tabular}




\section{References}

Barrett, M. (1982). The holophrastic hypothesis: Conceptual and empirical issues. Cognition, 11, 47-76.

Bloom, L., E. Tinker, \& C. Margulis (1993). The words children learn: Evidence for a verb bias in early vocabularies. Cognitive development, 8, 431-450.

Bolinger, D. (1971). The Phrasal Verb in English. Cambridge: Harvard University Press.

Brown, R. (1973). A First Language: The Early Stages. Cambridge, MA: Harvard University Press.

Bywater, F. V. (1969). A Proficiency Course in English. London: University of London Press.

Cameron-Faulkner, T., E. Lieven, \& M. Tomasello. (2003). A construction based analysis of child-directed speech. Cognitive Science, 27, 843-873.

Celce-Murcia, M., \& D. Larsen-Freeman. (1999). The grammar book: An ESL/EFL teacher's course. 2nd ed. Boston: Heinle \& Heinle.

Coady, J. (1997). L2 vocabulary acquisition: A synthesis of research. In: Coady J., \& T. Huckin (Eds.). Second language vocabulary acquisition. New York: Cambridge University Press, 225-237.

Cornell, Alan. (1985). Realistic Goals in Teaching and Learning Phrasal Verbs. IRAL, 23(4), 269-280.

Cowie, A. P., \& R. Mackin. (1993). Oxford Dictionary of Phrasal Verbs. New York: Oxford University Press.

Cullen, K., \& H. Sargeant. (1996). Chambers Dictionary of Phrasal Verbs. Edinburgh: Chambers Harrap Publishers.

Damon, W., R. M. Lerner (Series Eds.), D. Kuhn \& R. Siegler (Vol. Eds.) (2006). Handbook of child psychology: Vol. 2. Cognition, perception, and language. 6th ed. Hoboken, NJ: John Wiley \& Sons.

Darwin, C. M. \& L. S. Gray. (1999). Going after the Phrasal Verb: An Alternative Approach to Classification. TESOL Quarterly, 33, 65-83.

Davies, Mark. (2004-). BYU-BNC. (Based on the British National Corpus from OUP). $<$ http://corpus.byu.edu/bnc/>

De Laguna, G. (1927). Speech, its Function and Development. New Haven, Connecticut: Yale University Press.

Demuth, K., Culbertson, J., \& Alter, J. (2006). Word-minimality, epenthesis, and coda licensing in the acquisition of English. Language \& Speech, 49, 137-174.

Fillmore, Charles J. (1985). Syntactic intrusions and the notion of grammatical construction. Berkeley Linguistics Society, 11, 73-86.

Fillmore, Charles J. (1988). The mechanisms of 'Construction Grammar'. Berkeley Linguistics Society, 14, 35-55.

Folse, K. S. (2004). Vocabulary Myths: Applying Second Language Research to Classroom Teaching. Ann Arbor, Michigan: The University of Michigan Press.

Fraser, Bruce. (1965). An examination of the verb-particle construction in English. Cambridge, MA: M.I.T. PhD dissertation.

Fraser, Bruce. (1966). Some remarks on the verb-particle construction in English. In Report of the Seventh Annual Round Table Meeting on Linguistics and Language Studies. Washington: Georgetown University Press.

Fraser, Bruce. (1976). The Verb-Particle Combination in English. New York: Academic Press. 
Gardner, D. \& M. Davies. (2007). Pointing out frequent phrasal verbs: A corpus-based analysis. TESOL Quarterly, 41(2), 339-359.

Goldberg, A. E. (1995). Constructions: A construction grammar approach to argument structure. Chicago: University of Chicago Press.

Goldberg, A. E. (1998). Patterns of Experience in Patterns of Language. In: Tomasello, M. (ed.). The New Psychology of Language. Mahwah, NJ: Lawrence Erlbaum Associates, 203-219.

Goldberg, A. E. (1999). The Emergence of the Semantics of Argument Structure Constructions. In: MacWhinney, Brian (ed.). The Emergence of Language. Mahwah, NJ: Lawrence Erlbaum Associates, 197-212.

Goldberg, A. E. (2003). Constructions: A new theoretical approach to language. Trends in Cognitive Sciences, 7(5), 219-224.

Granger, S., C. Sanders, \& U. Connor. (eds.) (1995). Louvain Corpus of Native English Essays. Louvain-la-Neuve, Belgium: Presses Universitaires de Louvain.

Granger, S., E. Dagneaux, \& F. Meunier (eds.) (2002). International Corpus of Learner English. Handbook and CD-ROM. Version 1.1. Louvain-la-Neuve, Belgium: Presses Universitaires de Louvain.

Kellerman, E. (1983). Now you see it, now you don't. In: Gass, S., \& L. Selinker (Eds.). Language transfer in language learning. Rowley, MA: Newbury House, 112-134.

Klein, Eberhard. (1989). Vorkommen und Verwendung von Verb + PartikelKominationen in englischen Reifeprüfungsarbeiten. Neusprachliche Mitteilungen aus Wissenschaft und Praxis, 42(2), 84-90.

König, Ekkehard. (1973). Englische Syntax, vol. 2: Struktur des einfachen Satzes. Frankfurt am Main: Athenäum Fischer.

Lakoff, G. (1987). Women, Fire, and Dangerous Things: What Categories Reveal About the Mind. Chicago: University of Chicago Press.

Langacker, R. W. (1987). Foundations of Cognitive Grammar, Volume 1, Theoretical Prerequisites. Stanford: Stanford University Press.

Leopold, W. (1939-49). Speech Development of a Bilingual Child: A linguist's record, 4 volumes. Evanston, IL: Northwestern University Press.

Levenston, E. A. (1971). Over-indulgence and under-representation - aspects of mother-tongue interference. In: Nickel, G. (ed.). Papers in Contrastive Linguistics. New York: Cambridge University Press, 115-121.

Li, W., X. Zhang, C. Niu, Y. Jiang, \& R. Srihari. (2003). An Expert Lexicon Approach to Identifying English Phrasal Verbs. In: Proceedings of the 41st Annual Meeting of the Association for Computational Linguistics. Sapporo: 513520.

Live, Anna H. (1965). The discontinuous verb in English. Word, 21, 428-451.

MacWhinney, B. (1975). Pragmatic patterns in child syntax. Stanford Papers and Reports

on Child Language Development, 10, 153-165.

MacWhinney, B. (1982). Basic syntactic processes. In: Kuczaj, S. (Ed.). Language acquisition: Vol. 1. Syntax and semantics. Hillsdale, NJ: Lawrence Erlbaum, 73136.

MacWhinney, B. (1988). Competition and teachability. In: Schiefelbusch, R. \& M. Rice (Eds.). The teachability of language. New York: Cambridge University Press, 63-104.

MacWhinney, B. (2000). The CHILDES project: Tools for analyzing talk. 3rd ed. Vol. 2: The Database. Mahwah, NJ: Lawrence Erlbaum Associates.

Makkai, Adam. (1972). Idiom structure in English. The Hague: Mouton. 
McArthur, T. \& B. Atkins. (1974). Dictionnary of English Phrasal Verbs and their Idioms. London \& Glasgow: Collins.

McArthur, T. (1989). The long-neglected phrasal verb. English Today, 18(4), 38-44.

McCune, L. (1992). First words: A dynamic systems view. In: Ferguson, C., L. Menn, \& C. Stoel-Gammon (Eds.). Phonological development: Models, research, and implications. Parkton, MD: York Press.

McCune, L. (2006). Dynamic event words: From common cognition to varied linguistic expression. First Language, 26(2), 233-255.

Moon, Rosamund. (1997). Vocabulary connections: Multi-word items in English. In: McCarthy, M. \& N. Schmitt (Eds.). Vocabulary: Description, acquisition and pedagogy. Cambridge: Cambridge University Press, 40-63.

Moon, Rosamund. (1998). Fixed expressions and idioms in English: A corpus-based approach. Oxford: Clarendon Press.

Moon, Rosamund. (2005). Methaphor and Phrasal Verbs. In: Rundell, Michael (ed.) (2005). Macmillan Phrasal Verbs Plus. Oxford: Macmillan.

Ninio, A. (1992). The relation of children's single word utterances to single word utterances in the input. Journal of Child Language, 19, 87-110.

Rice, M., K. Wexler, \& S. Redmond (1999). Grammaticality judgments of an extended optional infinitive grammar: Evidence from English-speaking children with specific language impairment. Journal of Speech, Language, and Hearing Research, 42, 943-961.

Robert, S. \& G. Chapouthier. (2006). La mosaïque du langage. Marges linguistiques, $11,153-159$.

Rowland, C. (2007). Explaining errors in children's questions. Cognition, 104, 106134.

Rudzka-Ostyn, Brygida. (2003). Word Power: Phrasal Verbs and Compounds. A Cognitive Approach. Berlin/New York: Mouton de Gruyter.

Sawyer, J. H. (2000). Comments on Clayton M. Darwin and Loretta S. Gray's "Going after the phrasal verb: An alternative approach to classification": A reader reacts. TESOL Quarterly, 34(1), 151-159.

Schmidtke-Bode, K. (2009). Going-to-V and gonna-V in child language: A quantitative approach to constructional development. Cognitive Linguistics, 20(3), 509-538.

Shady, M. \& L. Gerken. (1999). Grammatical and caregiver cues in early sentence comprehension. Journal of Child Language, 26, 1-13.

Side, Richard. (1990). Phrasal verbs: sorting them out. ELT Journal, 44(2), 144-152.

Sinclair, John. (1996). The search for units of meaning. TEXTUS, 9(1), 75-106.

Slobin, D. (1973). Cognitive prerequisites for the development of grammar. In: Ferguson, C., D. Slobin (eds.). Studies of child language development. New York: Holt, Rinehart \& Winston, 175-208.

Slobin, D. (Ed.) (1985). The crosslinguistic study of language acquisition: Vol. 2. Theoretical issues. Hillsdale, NJ: Lawrence Erlbaum Associates.

Smiley, P., J. Huttenlocher (1995). Conceptual Development and the Child's Early Words for Events, Objects and Persons. In: Tomasello, M., W. Merriman (eds.). Beyond Names for Things: Young Children's Acquisition of Verbs. Hillsdale, NJ: Lawrence Erlbaum Associates, 21-61.

Stefanowitsch, A. \& S. Gries. (2003). Collostructions: investigating the interaction between words and constructions. International Journal of Corpus Linguistics, $8(2), 209-243$.

Tomasello, M. (1987). Learning to use prepositions: a case study. Journal of Child Language, 14, 79-98. 
Tomasello, M. (1992). First verbs: A case study of early grammatical development. Cambridge: Cambridge University Press.

Tomasello, M. (2003). Constructing a language: A usage-based theory of language acquisition. Cambridge, MA: Harvard University Press.

Vandeloise, C. (1987). L'expression du mouvement: présentation liminaire. Langue française, 76(1), 3-4.

Wood, D. (2004). An Empirical Investigation into the Facilitating Role of Automatized Lexical Phrases in Second Language Fluency Development. Journal of Language and Learning, 2(1), 27-50. 
